\title{
IDENTIFICAÇÃO BOTÂNICA DE RUPRECHTIA SALICIFOLIA (CHAM. \& SCHLTDL.) C.A. MEY. ${ }^{1}$
}

\author{
JOSÉ NEWTON CARDOSO MARCHIORI ${ }^{2}$ LEONARDO DOS SANTOS SABIN ${ }^{3}$
}

\begin{abstract}
RESUMO
É fornecida uma descrição botânica de Ruprechtia salicifolia (Cham. \& Schltdl.) C.A. Mey., com base em material coletado na mata ciliar do rio Ibicuí, município de Itaqui, Rio Grande do Sul.

Palavras-chave: Ruprechtia salicifolia, Polygonaceae.
\end{abstract}

\section{SUMMARY}

[Botanical identification of Ruprechtia salicifolia (Cham. \& Schltdl.) C.A. Mey.].

A botanical description of Ruprechtia salicifolia (Cham. \& Schltdl.) C.A. Mey. (Polygonaceae) is presented, based on specimens collected in the riparian forest of Ibicui river, in the municipality of Itaqui, Rio Grande do Sul state, Brazil.

Key words: Ruprechtia salicifolia, Polygonaceae.

\section{INTRODUÇÃO}

A flora sul-rio-grandense inclui duas espécies nativas do gênero Ruprechtia C.A. Mey. (Polygonaceae), ambas conhecidas, popularmente, como marmeleiros-do-mato. Destas, Ruprechtia laxiflora Meisn. é a mais importante, por ser euxilófora e de ampla distribuição geográfica no Estado. Ruprechtia salicifolia (Cham. \& Schltdl.) C.A. Mey., por sua vez, distingue-se, entre outros aspectos morfológicos, pelo porte reduzido do tronco, fator limitante à utilização, bem como pela distribuição restrita às matas ciliares do oeste do Estado.

Escassamente representada em herbários do Rio Grande do Sul, Ruprechtia salicifolia é espécie pouco conhecida, justificando a presente descrição e ilustração de seus caracteres morfológicos. Cabe salientar, ainda, que por sua

1 Recebido em 13-5-2009 e aceito para publicação em 2710-2009.

2 Engenheiro Florestal, Dr., Professor Titular do Departamento de Ciências Florestais, Universidade Federal de Santa Maria, RS. Bolsista de Produtividade em Pesquisa, CNPq - Brasil. balduinia@mail.ufsm.br

3 Biólogo, Curso de Pós-Graduação em Biologia Geral, URCAMP - Campus São Borja. ocorrência restrita a barrancas e trechos de mata aluvial, nas margens do rio Uruguai e no curso inferior de alguns de seus tributários, a espécie é potencialmente valiosa para trabalhos de bioengenharia, principalmente no oeste do Estado, com vistas ao controle da erosão no ambiente ripário.

A literatura recente dispõe de escassas publicações sobre a espécie, destacando-se, neste sentido, as contribuições de Pendry (2004), Troncoso (1987) e Cocucci (1961). Com base no referido trabalho de Pendry, Sobral et al. (2006) informam que Ruprechtia salicifolia é nativa na Argentina e Uruguai, além do Rio Grande do Sul. Menos sucinto, Lombardo (1964) informa que a espécie, de ocorrência restrita à margem de rios, na proximidade da água, apresenta folhagem caduca, flores masculinas com perianto "de seis divisões", flores femininas com três estiletes e perianto de "três divisões", além de fruto rombóide-fusciforme, incluso em perianto persistente.

Para Ruprechtia salicifolia, Brussa \& Grela (2007) referem a presença de folhas simples, alternas, lanceoladas, glabras, lustrosas, de margem inteira e base arredondada, bem como flores masculinas branco-amareladas, flores femi- 
ninas rosadas e aquênio persistente, "a modo de cúpula"; a floração é indicada para os meses de novembro e dezembro e a frutificação para fins do verão e outono.

\section{MATERIAL E MÉTODOS}

O material examinado foi especialmente coletado para este estudo na mata ciliar da margem direita do Rio Ibicuí, município de Itaqui Rio Grande do Sul (29 24' $15^{\circ}$ 'S e $56^{\circ} 40^{\prime}$ 32 "O), em ponto distante cerca de $200 \mathrm{~m}$, a leste da ponte rodoviária, e a $10 \mathrm{~km}$ da foz com o Rio Uruguai. As coletas de campo, incluindo material para exsicatas botânicas e amostras de madeira, foram realizadas em 18 de Abril de 2008 e 12 de Janeiro de 2009. O material botânico, após secagem em prensa, foi depositado no Herbário do Departamento de Ciências Florestais (HDCF), da Universidade Federal de Santa Maria.

Os desenhos de detalhes morfológicos são de autoria de Leonardo Paz Deble, a quem os autores registram agradecimentos.

Em gabinete, foram examinados os caracteres morfológicos de folhas, flores e frutos, constantes na descrição, apresentada na seqüência. A análise das estruturas foi realizada com lupa binocular Olympus SZ40, com régua de precisão $(0,5 \mathrm{~mm})$ e papel milimetrado. Informações relativas ao porte, floração, cor e consistência de estruturas, foram obtidas por observação a campo.

\section{DESCRIÇÃO MORFOLÓGICA}

Ruprechtia salicifolia (Cham. \& Schltdl.) C.A. Mey.; Mém. Acad. S. Pétersb., ser. 6, $2^{a}$ part. Sc. Nat. 6: 148-150, 1840.

Triplaris salicifolia Cham. \& Schltdl.; Linnaea 3: 56-58, 1828.

Arbusto ou arvoreta de $2-4 \mathrm{~m}$ de altura; tronco de $4-12 \mathrm{~cm}$ de diâmetro à altura do peito, com casca áspera, castanho-acinzentada. Ramos jovens sulcados, levemente pendentes, com entrenós de $2-4 \mathrm{~cm}$. Folhas alternas, subcoriáceas, elípticas ou elíptico-lanceoladas $(2,5-11 \mathrm{~cm} \times 1-2 \mathrm{~cm})$, inteiras, glabras, peninérveas, de ápice agudo e base obtusa ( $\mathrm{Fi}$ gura 1A); nervuras reticuladas e pouco marcadas, proeminentes em ambas as faces ( $\mathrm{Fi}$ gura $1 \mathrm{G})$. Pecíolos curtos $(2-5 \mathrm{~mm})$; ócreas reduzidas, efêmeras. Inflorescências, em racemos menores do que as folhas (Figura 1A). Flores unissexuais, zigomorfas; pedicelos articulados, de $8-10 \mathrm{~mm}$ de comprimento, e brácteas ocreiformes pubescentes (Figura $1 \mathrm{H}$ ). As masculinas, com 6 tépalas ovadas ou arredondadas, côncavas, cilioladas, 3 das quais são externas e as 3 internas alternas às primeiras; estames, 9, ligeiramente mais longos do que o perianto, organizados em dois ciclos, tendo o externo 6 estames e o interno 3; gineceu, atrofiado (Figura 1B). Flores femininas de 4 $5 \mathrm{~mm}$ de comprimento, com 3 tépalas externas elípticas (9-12 mm x 3-4 mm), persistentes, trinervadas, glabras, imbricadas, de ápice agudo, reto ou ligeiramente recurvo, persistentes e acrescentes após a antese; tépalas internas, também em número de 3 , muito menores do que as externas e de ápice arredondado; gineceu tricarpelar; estiletes curtos e estigmas lineares (Figura 1C). Fruto do tipo aquênio, elíptico (7 $-8 \mathrm{~mm} \times 3-4 \mathrm{~mm}$ ), trígono, com faces sulcadas longitudinalmente (Figura $1 \mathrm{~F}$ ) e totalmente recoberto pelo perigônio 3-lobulado (Figura 1D); estigmas persistentes, incurvos (Figura 1E). Semente oblonga, com endosperma ruminado e cotilédones foliáceos.

Etimologia: o nome genérico presta homenagem ao botânico tchecoslovaco Franz Josef Ruprecht (1814 - 1870), contemporâneo de Carl Anton von Meyer (1795 - 1855), que foi diretor do Jardim Botânico de São Petersburgo (Rússia). O epíteto específico alude à semelhança com as folhas do salgueiro (do latim salix, salgueiro e folium, folha).

Distribuição geográfica: elemento restrito às matas ciliares do curso médio e inferior do rio Uruguai e afluentes, nas províncias argentinas 


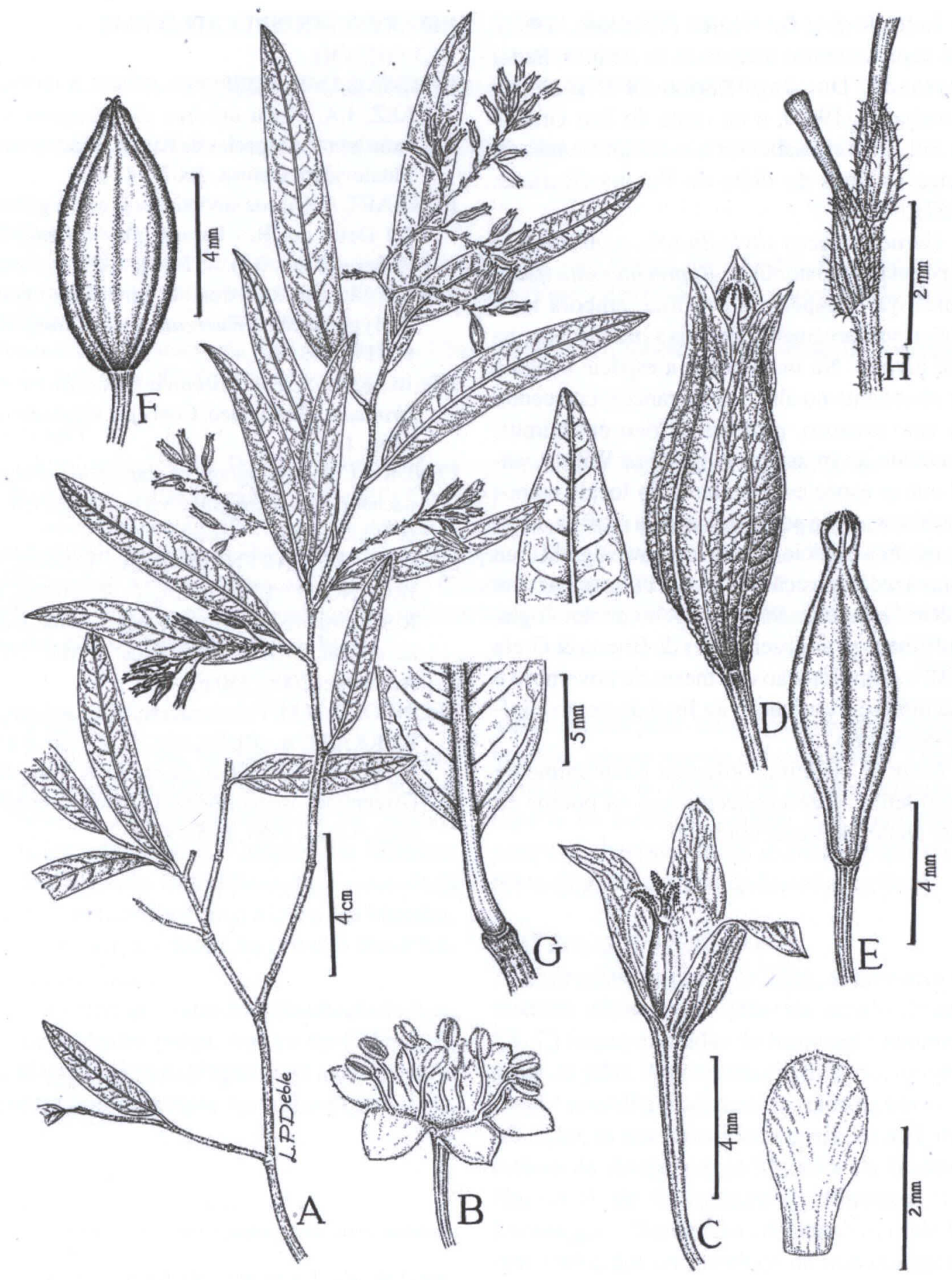

FIGURA 1 - Ruprechtia salicifolia (Cham. \& Schltdl.) C.A. Mey. A - Ramo frutífero. B - Flor masculina. C - Flor feminina, com tépalas externas e internas. D - Fruto com 3 estigmas incurvos, recoberto por cálice persistente. E - Aquênio jovem, tricarpelar, com estigmas persistentes. F - Aquênio elíptico, trígono, com faces sulcadas longitudinalmente. G - Detalhe do pecíolo, base e ápice da folha. H - Brácteas ocreiformes pubescentes, da inflorescência. 
de Entre Rios e Corrientes (Troncoso, 1987), nos departamentos uruguaios de Artigas, Salto, Paysandú, Durazno, Soriano e Rio Negro (Lombardo, 1964), e no oeste do Rio Grande do Sul. Importa salientar que a espécie não alcança as ilhas do delta do Paraná (Burkart, 1957).

Características silviculturais: a observação de populações naturais de Ruprechtia salicifolia, indica que a espécie é heliófila, embora tolerante a sombreamento de baixa intensidade, na fase juvenil. Na mata ciliar, a espécie chega a ser abundante no alto dos barrancos, crescendo em solo arenoso, profundo e rico em húmus, associado ao ingazeiro (Inga vera Willd.), entre outras espécies. Habitante de locais menos restritivos, sob o ponto de vista da reofilia, mesmo assim a espécie merece ser investigada com vistas à recomposição das matas ciliares no oeste do Rio Grande do Sul. A respeito da fenologia, confirmam-se as observações de Brussa \& Grela (2007), com floração nos meses de novembro e dezembro e frutificação ao final do verão e início do outono.

Usos: a madeira, utilizada eventualmente como lenha, é desconhecida sob os pontos de vista anatômico e tecnológico.

\section{REFERÊNCIAS BIBLIOGRÁFICAS}

BRUSSA SANTANDER, C.A.; GRELA GONZÁLEZ, I.A. Flora arbórea del Uruguay. Con énfasis en las espécies de Rivera y Tacuarembó. Montevideo: Cofusa, 2007. 542 p.

BURKART, A. Ojeada sinóptica sobre la vegetación del Delta del Rio Paraná. Darwiniana, San Isidro, v. 11, n. 3, p. 457-561, 1957.

COCUCCI, A.E. Revisión del género Ruprechtia (Polygonaceae). Kurtziana, Córdoba, v. 1, p. 217-249, 1961.

LOMBARDO, A. Flora arborea y arborescente del Uruguay. Montevideo: Concejo Departamental, 1964. $151 \mathrm{p}$.

PENDRY, C.A. Monograph of Ruprechtia (Polygonaceae). Systematic Botany Monographs, n. 67, p. 1-113, 1981.

SOBRAL, M.; JARENKOW, J.A.; BRACK, P.; IRGANG, B.; LAROCCA, J.; RODRIGUES, R.S. Flora arbórea e arborescente do Rio Grande do Sul, Brasil. São Carlos: RiMa ; Novo Ambiente, 2006. 350 p.

TRONCOSO, N.M. Polygonaceae, Poligonáceas.In: BURKART, A.; BURKART, N.S.T. de; BACIGALUPO, N.M. Flora ilustrada de Entre Rios (Argentina). Buenos Aires: Coleccion cientifica del I.N.T.A., 1987. p. 55-97. 